\title{
Ascorbic Acid Derivatives in the Sauvignon Blanc Cultivar (Vitis vinifera L.) During Berry Development in the Wellington and Elgin Regions
}

\author{
M. Dalicuba ${ }^{1 *}$, A.P. Nel, ${ }^{1}$ F.P. van Jaarsveld ${ }^{2}$
}

(1) Faculty of Applied Sciences, Department of Agriculture, Cape Peninsula University of Technology, Private Bag X8, Wellington, 7654, South Africa

(2) Post-harvest and Agro-Processing Technologies Division, ARC Infruitec-Nietvoorbij, Private Bag X5026, Stellenbosch, 7599 , South Africa

Submitted for publication: November 2020

Accepted for publication: August 2021

Keywords: Ascorbic acid, dehydroascorbic acid, 2,3-diketogulonic acid, L-threonate, wine pinking

The exposure of grapevines to unfavourable conditions such as drought, high or low temperature and pathogenic attack increases the production of reactive oxygen species, thus inducing oxidative stress. One of the most important non-enzymatic antioxidants is ascorbic acid, which is used by plants to protect themselves against these toxic oxygen intermediates. DHA, DKG and threonate are ascorbic acid metabolites that are found during ascorbic acid catabolism. This study was done in two regions, the one in Wellington, classified as a warmer climate, and the other in Elgin, classified as a cooler climate. In each region, two Sauvignon blanc vineyard blocks were selected, with north to south and east to west row directions. Vines were monitored during the growing season to investigate the trends in the development of ascorbic acid metabolites in both regions. Canopy management practices were done at different ripening stages. Grape berries were sampled at different phenological stages according to the Eichhorn Lorenz scale: E-L 32, E-L 34, E-L 35, E-L 37 and E-L 38. Ascorbic acid derivative concentrations in the two regions varied significantly in that Elgin showed higher concentrations than Wellington at E-L 32 and E-L 38. Both the cool and warm regions had high concentrations of threonate, with no significant difference among stages of ripeness. The DHA, DKG and threonate levels were the highest at the E-L 32 phenological stage for both regions, with no significant differences among the other phenological stages, especially for DHA derivative concentrations. No significant effect on the DHA, DKG and threonate levels of the grapes was observed between row directions in each region.

\section{INTRODUCTION}

Ascorbic acid, also known as vitamin $\mathrm{C}$, is defined as the generic term for all compounds exhibiting the biological activity of L-ascorbic acid (Lee \& Kader, 2000). L-ascorbic acid was first isolated by Svirbely and Szent-Györgyi (1932), and its structure was established in 1933 (Iqbal et al., 2004). Ascorbic acid is naturally present in grapes, but the levels are low (below $10 \mathrm{mg} / \mathrm{L}$ ) (Cojocaru \& Antoce, 2012). Additions of ascorbic acid to wine were first allowed in the USA in 1957 (Cojocaru \& Antoce, 2012). Ascorbic acid is commonly used as an antioxidant and to prevent pinking in certain grape musts and wines (Bradshaw et al., 2004), and has also been shown to have beneficially contributed to wine colour and flavour when added at bottling (Skouroumounis et al., 2005a). Simpson (1977) defines pinking as "the troublesome discolouration" that develops during the storage of white wines. He later adds that it develops over several days, but most likely after vinification or when the wine is no longer protected by a $\mathrm{CO}_{2}$ blanket. This led to the discovery that pinking occurs after contact with air (Simpson, 1980). Andrea-Silva et al. (2014) defines pinking as "the appearance of a salmon-red blush in white bottled wines produced exclusively from white varieties". Therefore, a comprehensive definition of pinking could be established, as follows: Pinking, or oxidative pinking, is the slight discolouration of white wines from a pinkish to a salmonred blush colour, affected by certain oenological processes before and after fermentation until storage during which the wine could come into contact with air (Nel et al., 2020). Moreover, the importance of ascorbic acid is realised in the white juice of aromatic varieties in which the preservation of the aromatics is essential for wine quality This is achieved through the addition of an ascorbic acid and sulphur dioxide $\left(\mathrm{SO}_{2}\right)$ combination, which acts as an aggressive antioxidant treatment (Skouroumounis et al., 2005b). 
The biochemistry of ascorbic acid in plants is poorly understood (Davies et al., 2007) and, according to the latest findings, there is insufficient information on the concentrations of ascorbic acid in the grape berry during ripening and in the resulting wine (Andrea-Silva et al., 2014). Ascorbic acid, although naturally present in grapes, rapidly disappears throughout the ripening process and with exposure to oxygen during the crushing of grapes in the winemaking process (Iqbal et al., 2004). In addition to the importance of ascorbic acid in winemaking, this acid is vital for human growth and the maintenance of healthy bones, teeth, gums, ligaments and blood vessels as it acts as an antioxidant that chemically binds and neutralises the tissue-damaging effects of free radicals (Iqbal et al., 2004). L-ascorbic acid is found all over the plant world, often in significant quantities and distributed throughout the plant (Davey et al., 2000). The grape berry, however, is not among those fruit with a high ascorbic acid content. It has approximately $11 \mathrm{mg}$ per $100 \mathrm{~g}$ fresh weight, compared to the $200 \mathrm{mg}$ per $100 \mathrm{~g}$ fresh weight for blackcurrants and 50 $\mathrm{mg}$ per $100 \mathrm{~g}$ fresh weight for lemons (Davey et al., 2000). Ascorbic acid is a precursor of the synthesis of tartaric and oxalic acids (Aziz \& Sulaimani, 2013).

Knowledge of ascorbic acid in grape berries under South African growing conditions is limited and inconclusive. While there is increasing interest in ascorbic acid accumulation in grape berries, little is known about the effect of terroir and vineyard practices on the concentration of ascorbic acid and its derivatives. Considering the importance of ascorbic acid for wine quality, the concentrations in grapes during berry development and in the resulting wine warrant further research. Consequently, climatic conditions, viticultural practices and post-harvest grape-handling processes that maintain high levels of ascorbic acid would be beneficial to make distinctive decisions on ascorbic acid addition in combination with $\mathrm{SO}_{2}$. In the present study, the aim was to monitor the levels of ascorbic acid and its derivatives in Sauvignon blanc (Vitis vinifera L.) during berry development and in wine in South Africa.

\section{MATERIALS AND METHODS}

\section{Location of the experimental sites}

The work was done during the season from September 2018 to March 2019 on Vitis vinifera L. cv. Sauvignon blanc grapevines rooted on Richter 99 . Two study sites were selected in two diverse climatic regions - Wellington (warm region) $\left(33.5778^{\circ} \mathrm{S}, 19.0202^{\circ} \mathrm{E}\right)$ and Elgin (cool region) $\left(34.2169^{\circ} \mathrm{S}\right.$, $19.0560^{\circ} \mathrm{E}$ ). The Sauvignon blanc vines in Wellington were planted in 1983 and those in Elgin in 2003, with $2.5 \mathrm{~m} \times 1.5$ $\mathrm{m}$ vineyard spacing. The vines were spur pruned to two buds per spur on a four-strand double lengthened Perold system (SDLP). Grapevines were sampled on one farm in the Wellington district, Schalk Burger and Sons, and one farm in the Elgin district, Paul Wallace Farm. Canopy management practices were planned and performed carefully when the berries were peppercorn size $-4 \mathrm{~mm}$ diameter - to create a favourable microclimate for berry composition (Coombe, 1995). The timing of canopy management was adapted in such a way that the physiological cycle of the grapevine was favourable for the required grape composition and wine style to be achieved.

\section{Wellington}

Wellington is a town in the Western Cape Winelands, located $75 \mathrm{~km}$ north-east of Cape Town, and has an altitude of $127 \mathrm{~m}$ above sea level. Wellington officially falls under the Drakenstein local municipality. It usually receives about $585 \mathrm{~mm}$ of rain per year, with the lowest rainfall $(10 \mathrm{~mm})$ in February and the highest $(105 \mathrm{~mm}$ ) in June (South Africa Explorer, 2017). Wellington has a Mediterranean climate, with February being the warmest month, with an average maximum day temperature of $30^{\circ} \mathrm{C}$ and an average minimum night temperature of $17.7^{\circ} \mathrm{C}$. July is the coldest month, with an average maximum day temperature of $14.8^{\circ} \mathrm{C}$ and an average minimum night temperature of $6.3^{\circ} \mathrm{C}$ (South Africa Explorer, 2017).

\section{Elgin}

Elgin is situated in the Overberg region close to the Southern Cape Coast, about $70 \mathrm{~km}$ east of Cape Town. This region is just beyond the Hottentots-Holland mountain range and is centred around the village of Grabouw. The Elgin Valley is separated from the sea by a narrow range of mountains with altitudes ranging from 300 metres to 600 metres above sea level. These conditions create a cool climate, which is essential for the production of deciduous fruits (Stofberg, 2018). Grabouw also has a Mediterranean climate with an annual rainfall of about $990 \mathrm{~mm}$. The highest rainfall is usually during June (long-term mean of $168 \mathrm{~mm}$ ) and the lowest rainfall in February $(22 \mathrm{~mm})$. February is also the warmest month, with an average maximum day temperature of $24.8^{\circ} \mathrm{C}$ and an average minimum night temperature of $14.1^{\circ} \mathrm{C}$. July is the coldest month, with an average maximum day temperature of $14.8^{\circ} \mathrm{C}$ and an average minimum night temperature of $6.4^{\circ} \mathrm{C}$ (South Africa Explorer, 2017).

\section{Treatments \\ Viticultural treatments}

Four vineyard blocks of Sauvignon blanc were selected (two on each farm, as described above) with different row orientations (north to south and east to west). The sizes of the vineyard blocks were as follows: The Wellington northto-south block was 2.3 hectares and the east-to-west block was 1.2 hectares. In Elgin, the north-to-south block was one hectare, and the east-to-west block was 1.8 hectares. Wellington's north-to-south block had 115 grapevines per row and the east-to-west block had 80 grapevines per row. Elgin's north-to-south block had 78 grapevines per row and the eastto-west block had 106 grapevines per row. On each farm, six rows in each vineyard block were selected randomly (northto-south and east-to-west row orientation) for the experiment and marked using danger tape. Three of the six rows were selected as treatments for canopy management practices, such as suckering at $10 \mathrm{~cm}$ shoot lengths (the removal of unwanted shoots from cordons, arms or nodes on spurs or canes). Wellington was suckered at the end of September and Elgin was suckered at the end of October. Suckering and leaf removal (three to four leaves removed at the bunch 
TABLE 1

Scale and descriptions of Eichhorn Lorenz E-L stages (adapted form Coombe, 1995)

\begin{tabular}{ll}
\hline E-L stage & Description \\
\hline E-L 32 & berry pea size \\
E-L 34 & berries still hard and green \\
E-L 35 & véraison \\
E-L 37 & berries not quite ripe \\
E-L 38 & berries harvest ripe \\
\hline
\end{tabular}

zone depending on the canopy density - assessed visually - when berries begin to soften and sugar starts increasing) were done on the sides that received morning sunlight and in all four vineyards blocks so that vine bunches were not exposed directly to sunlight. All the suckered rows were also topped (when shoots were higher than the anchor pole, at about 100 to $150 \mathrm{~cm}$ ), leaves were removed from the bunch zone when berries started to soften, and the vine stem and the sections under the cordon arms were cleaned by removing all the water shoots (at all phenological ripening stages). The other three rows of the six rows in each vineyard block (north-to-south and east-to-west row orientation) were left unhindered (control), and no canopy management practices were performed. The treatments were as follows:

\section{Sample handling up to harvest}

Sampling and transportation were performed early in the morning (from 04:00 to 10:00, during the cooler part of the day. Each of the rows, suckered or non-suckered, was sampled separately, with 900 berries per row (hence 900 x $6=5400$ berries for the north-to-south and east-to-west suckered and non-suckered vineyard rows), sampled from bunches randomly (top, middle, bottom and back of the bunch) from each row across the six rows per vineyard block (north-to-south or east-to-west row orientation) and the berries were pulled off from the septum when sampled. The 900 sampled berries from each row, suckered or nonsuckered, were divided by three to get three replicates per row. Berries were sampled at five different phenological stages berry pea size, berries still hard and green, véraison, berries not quite ripe, and berries harvest ripe (Table 1). The date of the beginning of each phenological stage was determined visually for every block. The berries were placed in plastic bags for transportation to minimise damage and kept in a cooler box on ice to minimise temperature fluctuations.

\section{Sample preparation}

Fresh samples were prepared and analysed on the day of sampling. After sampling, 300 berries (from the 900 berries per vineyard row) were put into a $5 \mathrm{~L}$ jug and crushed to obtain the juice. In preparing the juice, dry ice was used to cover the extracted juice to isolate the juice from oxygen. The juice was immediately transferred to $15 \mathrm{~mL}$ falcon tubes and filled. The samples were taken to the laboratories of the Central Analytical Facilities (CAF) at Stellenbosch University for analysis of ascorbic acid, dehydroascorbic acid (DHA), 2,3-diketogulonic acid (DKG) and L-threonate.

\section{Protocols for analyses \\ Liquid chromatography-mass spectrometry (LC-MS) analysis}

A Waters Acquity ultra-performance liquid chromatography (UPLC) coupled to a Xevo TQ-MS mass spectrometer (MS/ MS) (Agilent manufacture) was used for high-resolution UPLC-MS/MS analysis. The separation was achieved on an Acquity HSS T3 column $(2.1$ x $100 \mathrm{~mm} ; 1.7 \mu \mathrm{m}$ particle size) at $40^{\circ} \mathrm{C}$ and a flow rate of $0.25 \mathrm{~mL} / \mathrm{min}$. Data was acquired with multiple reaction monitoring (MRM) using electrospray negative ionisation. The operating parameters used were as follows: capillary voltage, $3.5 \mathrm{~V}$; cone voltage range, $10 \mathrm{~V}$ to $35 \mathrm{~V}$; collision energy range, $5 \mathrm{eV}$ to $40 \mathrm{eV}$; source temperature, $140^{\circ} \mathrm{C}$; desolvation temperature, $400^{\circ} \mathrm{C}$; desolvation gas, $800 \mathrm{~L} / \mathrm{h}$; and cone gas, $50 \mathrm{~L} / \mathrm{h}$. An injection volume of $5 \mu \mathrm{L}$ was used, and the mobile phase consisted of water acidified with $0.1 \%$ formic acid and acetonitrile acidified with $0.1 \%$ formic acid.

Test for pinking susceptibility of Sauvignon blanc wine One hundred and twenty microlitres of $30 \%(\mathrm{w} / \mathrm{v})$ hydrogen peroxide $\left(\mathrm{H}_{2} \mathrm{O}_{2}\right)$ was added to a $50 \mathrm{~mL}$ volumetric flask and filled up to the mark with distilled water to obtain a $0.072 \%$ $(\mathrm{w} / \mathrm{v})$ hydrogen peroxide solution. One $\mathrm{mL}$ of $0.072 \%(\mathrm{w} / \mathrm{v})$ $\mathrm{H}_{2} \mathrm{O}_{2}$ was added to each sample. The falcon tubes were closed immediately after the addition of $\mathrm{H}_{2} \mathrm{O}_{2}$ to prevent any oxidation and then mixed very gently by tilting up and down. The samples were allowed to stand in a dark cupboard for eight hours. The optical density at $500 \mathrm{~nm}$ of samples was read the next day, measured against a control sample with no added $\mathrm{H}_{2} \mathrm{O}_{2}$ to zero the spectrophotometer (Avantor, 6346001 number, UV-1600PC model).

\section{Statistical analysis}

Statistical differences between treatments were determined by analysis of variance (ANOVA). A split-plot experimental design with treatments as the main plot factor and stages as the sub-plot factor was used in the analysis. A combined ANOVA of farms and row orientations was performed. The homogeneity of variance was verified by Levene's test (Levene, 1960) and the normality of the standardised residuals was verified by the Shapiro Wilk test (Shapiro \& Wilk, 1965). ANOVA was performed using the GLM procedure of SAS statistical software (Version 9.4, SAS 
Institute Inc., Cary, NC, USA). Fisher's least significant difference was calculated at the $5 \%$ level of significance to compare treatment means (Ott, 1998). A probability level of $5 \%$ was considered significant for all significance tests.

\section{RESULTS AND DISCUSSION}

The differences in behaviour/trends of the ascorbic acid derivatives between the two regions, Wellington and Elgin, were measured for the 2018/2019 vintage.

\section{Determination of trends in the development of ascorbic acid metabolites in Wellington and Elgin}

The response in DHA, DKG and threonate concentration levels during berry development to different treatments, i.e. suckered versus non-suckered, north-to-south versus eastto-west row orientations between two climatic regions is shown in Figs 1 to 3. Dehydroascorbic acid concentrations (Fig. 1) in the Wellington grapes varied throughout all the stages of ripeness (E-L 32 to E-L 38) for the north to southorientated suckered blocks, with suckered rows having higher DHA concentrations at E-L 33 and 35 than E-L 32, 37 and 38. The east-to-west suckered blocks, however, had significantly higher concentrations of DHA at E-L 32. The results for Elgin show high levels of DHA at E-L 32, after which it decreased from E-L 33 to E-L 38. The DHA initially yielded DKG, which was then oxidised to L-threonate, possibly being the reason that DHA was detected at lower concentrations, while the DKG and L-threonate were present at higher concentrations. This evidence is in agreement with that of Shimada and Ko (2008), showing that ascorbic acid oxidase catalyses the oxidation of ascorbic acid to yield dehydroascorbic acid, followed by the decomposition of DHA to DKG and other derivatives. The immediate oxidation product of ascorbate is DHA, which can be hydrolysed quickly and irreversibly to DKG (Dewhirst \& Fry, 2015) as a result of enzymatic or non-enzymatic reactions, or is reduced to ascorbic acid by dehydroascorbate reductase, which uses glutathione (GSH) as a reductant (Cruz-Rus et al., 2011). Saito and Kasai (1969) administered 1-[1-14C] ascorbic acid to immature grape berries and discovered that, after 24 hours of metabolism, $72 \%$ of the $14 \mathrm{C}$ in the soluble fraction was recovered as tartaric acid, with most of the $14 \mathrm{C}$ in the carboxyl carbon. Another study, by Saito and Loewus (1979), showed that tartaric acid labelling from ascorbic acid in grapes was highest in the days preceding or at anthesis, but declined with berry maturity. In addition, a part of oxidised ascorbic acid can be further catabolised to smaller molecules, such as L-threonate, L-glyceric acid and oxalic acid (Ishikawa et al., 2006; Cruz-Rus et al., 2011). According to Huang et al. (2014), oxalic acid, L-threonate, and L-tartaric acid are the main products of ascorbic acid catabolism. DHA can be hydrolysed to DKG or oxidised to a range of products, such as L-threonate, oxalic acid (OxA), and their esters (Truffault et al., 2017). If the exclusion of reactive oxygen species (ROS) limits oxidation, DHA in aqueous solution predominantly undergoes hydrolysis to form DKG. This hydrolysis is probably irreversible in vivo (Wechtersbach et al., 2011). Diketogulonic acid itself can be oxidised into an unknown compound, which itself can be further oxidised to L-threonate; therefore, DKG can act as an antioxidant like ascorbic acid and DHA (Parsons \& Fry, 2012).

The DKG derivative was also observed during the ripening period, between E-L 32 and E-L38 (Fig. 2). The results show that DKG was the second derivative to have a higher concentration of ascorbic acid catabolism after

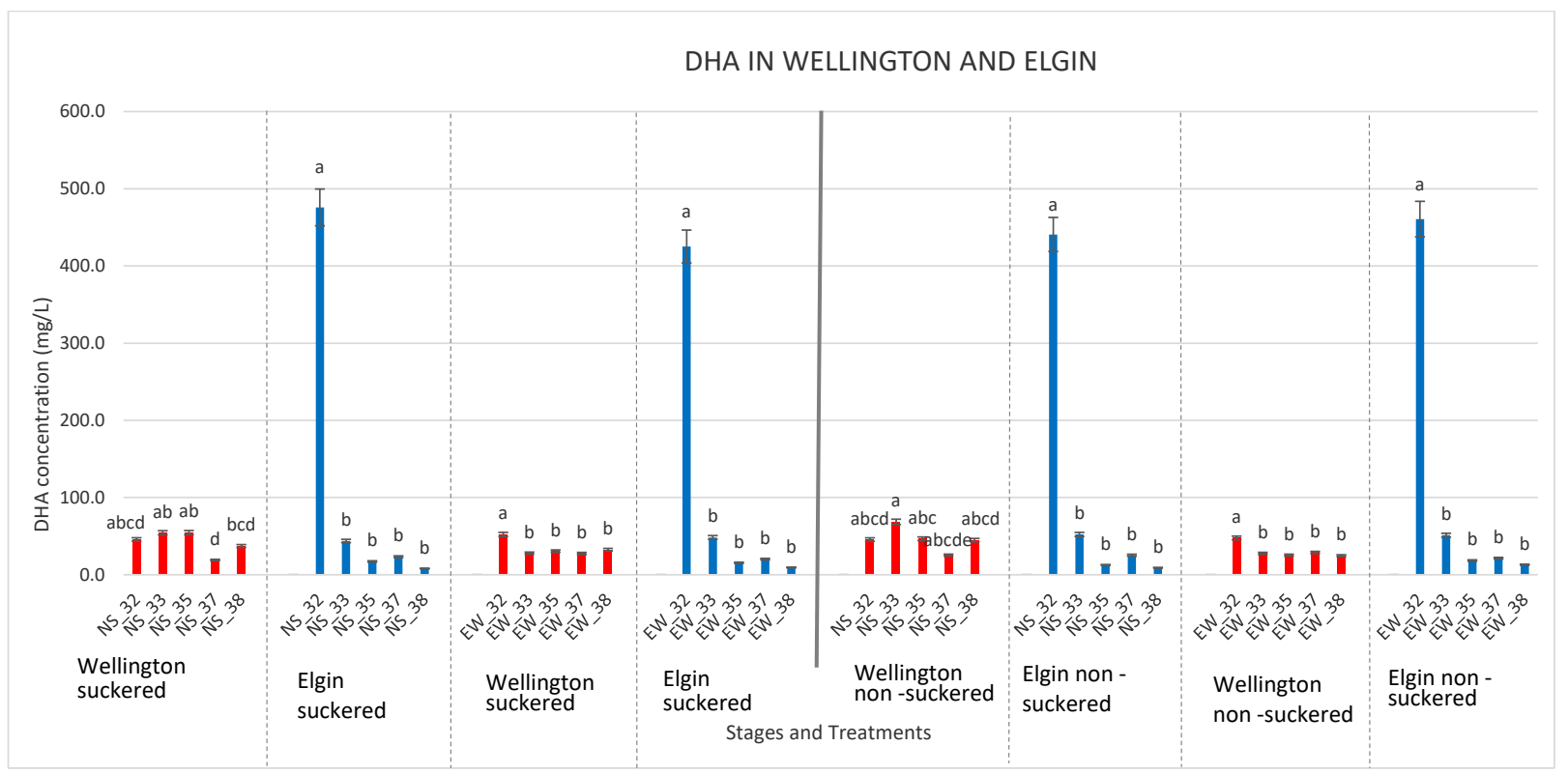

FIGURE 1

Accumulation of dehydroascorbic acid (DHA) derivative in the berry during grapevine growth in two climatic regions Wellington (red) and Elgin (blue) - for the suckered and non-suckered treatments and north-south and east-west row orientations, and at the five phenological stages. Data are given in means with standard deviations, and bars with the same letters are not significantly different $(\mathrm{p} \geq 0.05)$. 


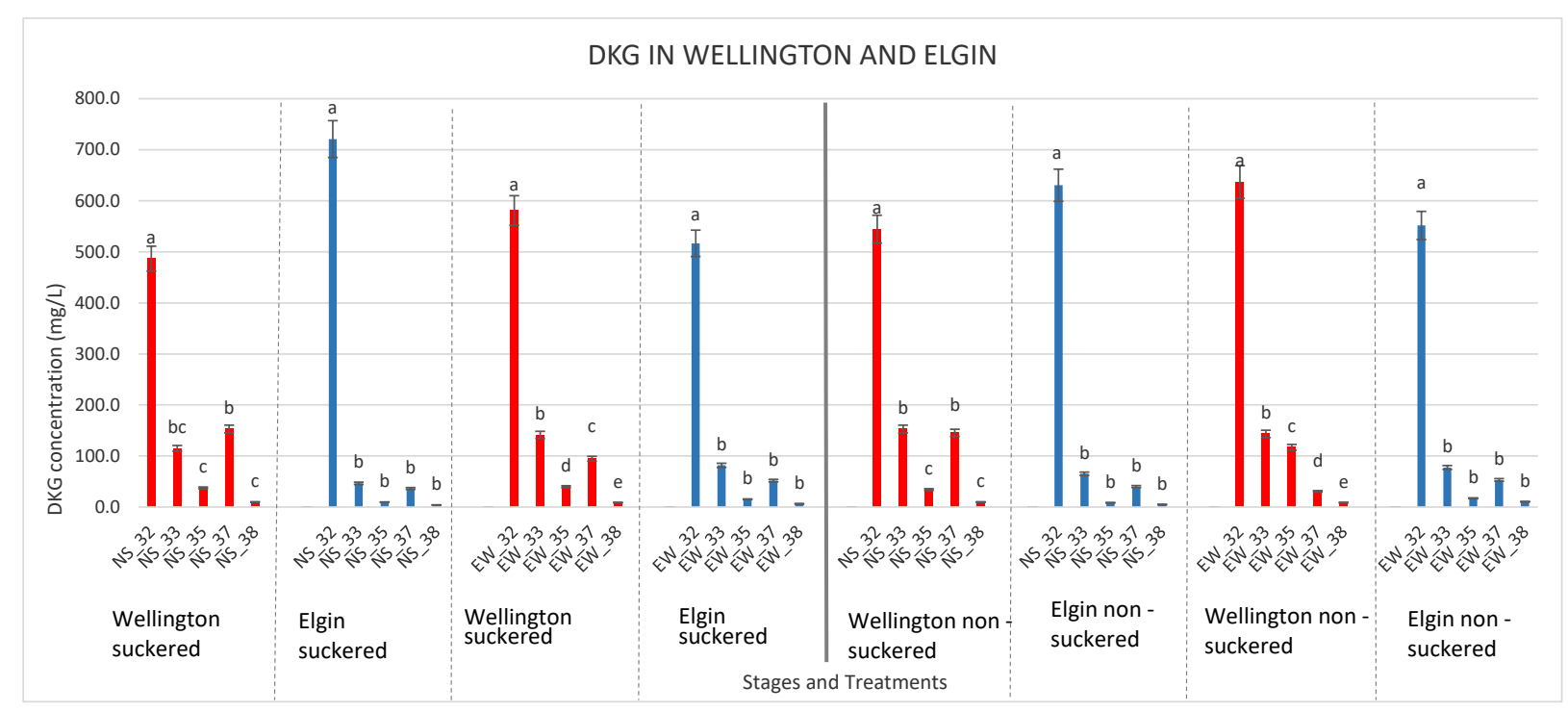

FIGURE 2

Accumulation of diketogulonic acid (DKG) derivative in the berry during grapevine growth in two climatic regions - Wellington (red) and Elgin (blue) for the suckered and non-suckered treatments and north-south and east-west row orientations. The results show the data collected per region and individual treatments on each farm (means and standard deviation). The bars and the letters show the differences between the regions in each of the vineyard blocks and for each of the phenological stages. Data are given in means, and bars with the same letters are not significantly different $(p \geq 0.05)$. Those with different letters are significantly different $(\mathrm{p} \leq 0.05)$.

DHA. Both Wellington and Elgin had higher concentrations of DKG at all the E-L stages, with E-L 32 having the highest concentrations. This may be the result of the DKG, which is the second derivative after the DHA is oxidised. The treatments of suckered and non-suckered vines with north-south and east-west row directions did not have an effect on the concentrations of DKG derivatives. Bradshaw et al. (2011) report that studies conducted on the fate of the DKG either investigated the direct degradation of DKG or its degradation after formation from DHA. DKG generates a wide variety of compounds via numerous mechanisms, including decarboxylation, oxidative decarboxylation, dehydration, keto-enol rearrangements, cyclisation, and benzylic rearrangements (Bradshaw et al., 2011). L-threonate, as the end product of ascorbic acid catabolism, indicates high ascorbic acid metabolism at all five ripening stages in this study for both farms. L-threonate, on the other hand, is quite stable in an oxidative environment (Deutsch, 1998b). Oxalic acid and L-threonate are more stable, probably explaining why they are better-known endproducts of ascorbate degradation (Yang \& Loewus, 1975). In summary, DHA, DKG and L-threonate concentrations for the Wellington and Elgin districts varied with ripeness (E-L 32 to E-L 38) for both row orientations and stages of ripeness. L-threonate (Fig. 3) had the highest concentration among the DHA and DKG ascorbic acid derivatives at all the E-L stages. Both farms had the highest concentrations of threonic acid derivative as a by-product of DKG at all the ripening stages, with Wellington having the highest concentrations at E-L 32 for threonic acid compared to Elgin (Fig. 3). The concentrations of L-threonate ascorbic acid derivative were very low at E-L 38 for both farms, which could be the results of the increase in sugar content and decrease in acid during the ripening period of the grapes. L-threonate can alternatively be produced from DKG degradation. Major oxidative end products of irreversible DHA degradation, both in vitro and in most plant species in vivo, are L-threonate plus oxalic acid (OxA), which are formed by oxidative cleavage of the C-2-C-3 bond (Deutsch, 1998a). L-threonate, on the other hand, is quite stable in an oxidative environment (Penney \& Zilva, 1945), and this was reflected in the higher derivative concentrations on each farm for both row orientations (north-south and east-west). Due to the possible influence of climatic differences between the wine grape-growing regions of Wellington and Elgin (Figs 1 to 3), the progression of grape ripening and the ascorbic acid derivative concentrations varied greatly. It was observed that the ascorbic acid derivative concentrations decreased after E-L 32 for both growing regions. In most fruits, such as grapes, acidity decreases at véraison, while sugar content increases during ripening (Gautier et al., 2008; Mellidou et al., 2012). The decrease in the ascorbic acid derivative content can be ascribed to abiotic factors, such as light intensity, light quality and temperature (Matei et al., 2009). These environmental factors then result in the instability of ascorbic acid and its derivates. The ascorbic acid derivative content of grapes is positively influenced by light intensity during growth (Matei et al., 2009) and negatively influenced by climacteric conditions (rain) (Matei, 2008).

One can observe that the rate of catabolism for ascorbic acid derivatives in grapes was almost unchanged during all the ripening periods from E-L 33 to E-L 37, and it decreased gradually at E-L 38 (Figs 1 to 3). That could be because, as the grapes enlarge and accumulate sugar, the total acid concentration in the grapes decreases. However, there were differences between the two regions at the E-L 38 stage for 


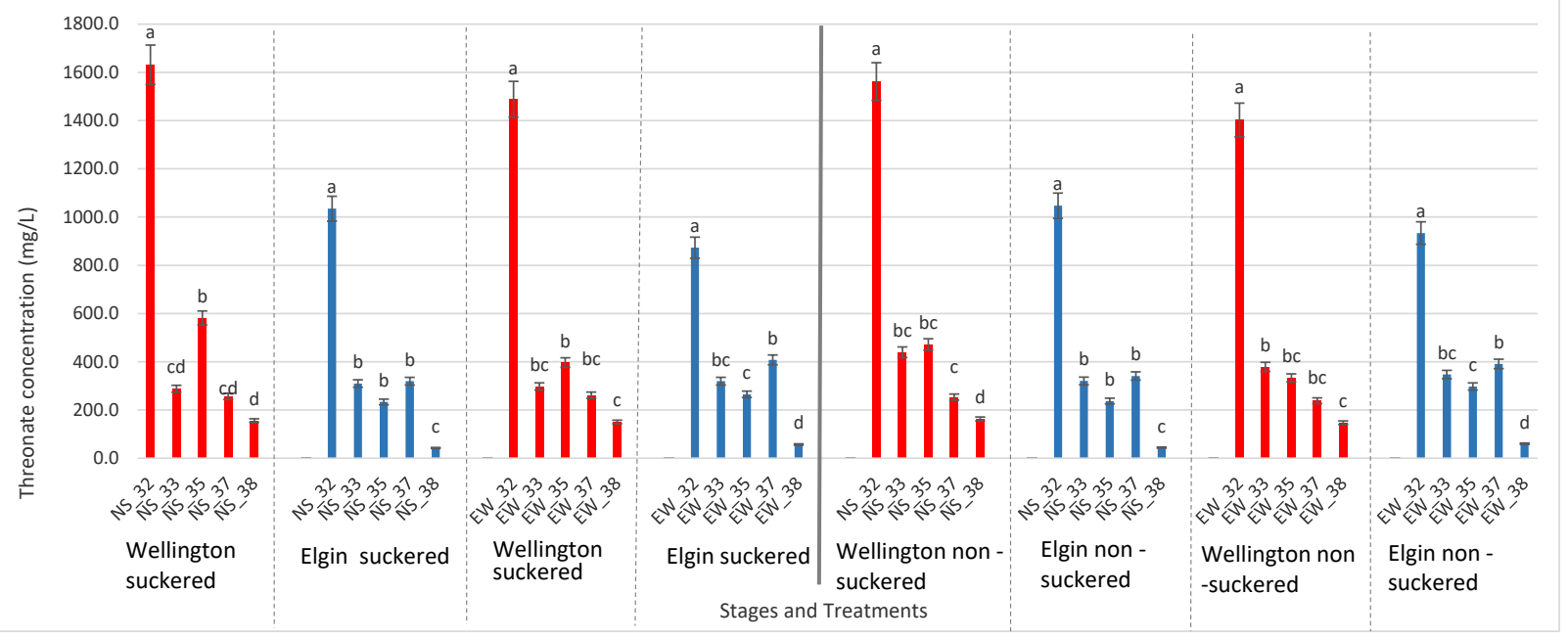

FIGURE 3

Accumulation of L-threonate derivative in the berry during grapevine growth in two climatic regions - Wellington (red) and Elgin (blue) - for the suckered and non-suckered treatments and north-south and east-west row orientations. The results show the data collected per region and individual treatments on each farm (means and standard deviation). The bars and the letters show the differences between the regions in each of the vineyard blocks and for each of the phenological stages. Data are given in means, and bars with the same letters are not significantly different $(\mathrm{p} \geq 0.05)$. Those with different letters are significantly different $(p \leq 0.05)$.

DKG and threonate concentration during the ripening period.

The treatments of suckered and non-suckered vineyard rows did not show significant differences for all the ascorbic acid derivatives. The idea behind suckering and leaf removal in the bunch zone was to increase light penetration to the berries. A significant number of studies have investigated the effects of leaf removal on berry development and ripening (Du Plessis et al., 2017) and that, depending on the cultivar, the objectives range from improving the acid balance (Baiano et al., 2015; Du Plessis et al., 2017) and improving anthocyanin/colour stability (Yu et al., 2016; Pastore et al., 2017) to increasing specific secondary metabolites such as volatile aroma precursors (Young et al., 2016) and lowering metabolites that are perceived as negative in the grapes or wines (Sidhu et al., 2015).

In viticulture, many canopy management practices are performed to optimise light exposure to drive the photosynthesis of the canopy (Clingeleffer, 2010). These studies have all highlighted the adaptability of the grapevine berries to the changed microclimate and have also provided scope to investigate mechanisms of perceiving and adapting to the stresses linked to changes in microclimate (Du Plessis et al., 2017). According to Hamner et al. (1945), the light activates ascorbic acid biosynthesis. In grapes, the ascorbic acid content was twice as high in fruits grown under high light conditions compared to fruits growing in low light conditions (Cruz-Rus et al., 2010). Padayatty et al. (2003) reported that areas with cool night temperatures produce citrus fruits with higher ascorbic acid concentrations, and hot tropical areas produce fruit with lower concentrations of ascorbic acid. In most fruits, acidity decreases, while sugar content increases, during ripening (Gautier et al., 2008;
Mellidou et al., 2012). However, the change in ascorbic acid levels during fruit ripening is a trait dependent on the species. In tomatoes (Badejo et al., 2011), grapes (CruzRus et al., 2010) and strawberries (Cruz-Rus et al., 2011), ascorbate content increases as the fruit ripen.

\section{Determination of the pinking phenomenon associated} with the Sauvignon blanc cultivar between two climates The absorbance values in Fig. 4 indicate the pinking susceptibility of wines from the two regions. There was a significant difference in the potential to pink between Wellington and Elgin. Sauvignon blanc wines from northsouth and east-west, suckered and non-suckered rows in Elgin showed susceptibility to pink. The wines from Wellington did not show any pinking potential. The differences in pinking between the two regions could be attributed to the fact that cooler grapes can hold more dissolved oxygen than warmer grapes and this may lead to the appearance of a pink colour (Nel \& Van Jaarsveld, 2018). According to Simpson (1977), the increased pinking phenomenon in some vintages coincided with an increase in the use of colder fermentation and inert gases such as nitrogen and carbon dioxide, along with closed containers to protect against oxidation. Wines produced under these conditions are often those exhibiting a higher susceptibility to pinking when exposed to small amounts of air, often during bottling, and will become brown when exposed to oxygen further at a later stage, or when bottled with a high dissolved oxygen content. This is in agreement with observations made by Singleton (1972).

Several scientific publications examine possible compounds that promote pinking, but the findings do not all concur. To date, there still is uncertainty about which 


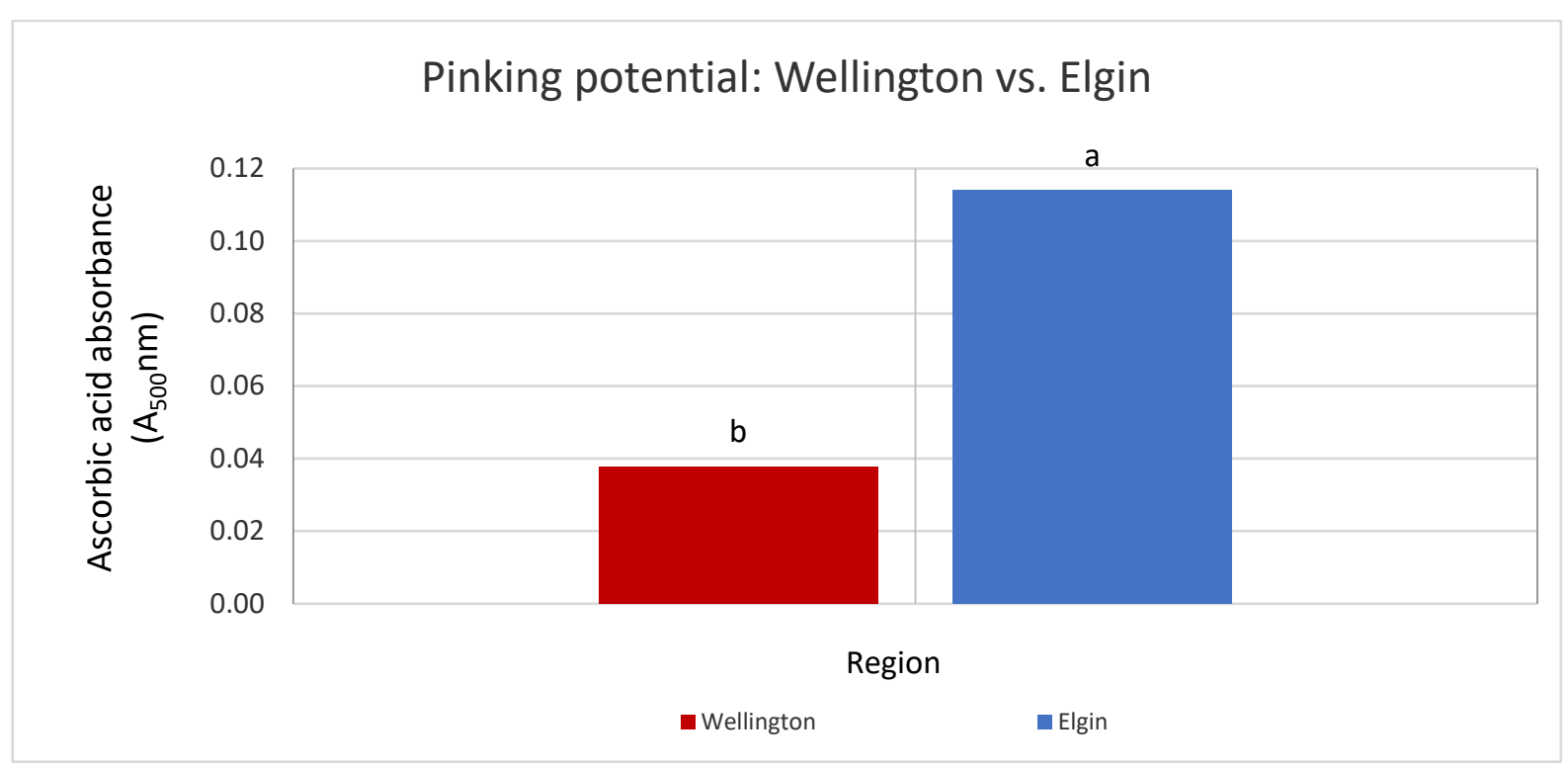

FIGURE 4

Pinking potential of Sauvignon blanc wines from two climatic regions - Wellington and Elgin. Values are means $(\mathrm{n}=12)$ for each farm for all treatments, i.e. north-south and east-west suckered and non-suckered rows. Data are given in means, and bars with different letters show a significant difference $(\mathrm{p} \leq 0.05)$.

compound causes pinking (Andrea-Silva et al., 2014). Therefore, research about pinking is still ongoing. When ascorbic acid (vitamin C) is used in the presence of oxygen in the juice/wine, the ascorbic acid is oxidised to DHA, ultimately resulting in the formation of hydrogen peroxide $\left(\mathrm{H}_{2} \mathrm{O}_{2}\right)$ (Barril et al., 2016). Hydrogen peroxide, being a strong oxidising agent, requires sulphur dioxide to bind and neutralise the wine/juice (Bradshaw et al., 2011). Although ascorbic acid is a very good antioxidant, it has the ability to reduce the shelf life of Sauvignon blanc, and the wines quickly become brown after bottling (Barril et al., 2016). According to Nel and Van Jaarsveld (2018), it is important to consider the free $\mathrm{SO}_{2}$ concentration of the wine at 35 to $45 \mathrm{mg} / \mathrm{L}$ if ascorbic acid is used, and when working with dry ice and inert gas it is also important to keep the $\mathrm{SO}_{2}$ of the wine as close as possible to 35 to $45 \mathrm{mg} / \mathrm{L}$. Ascorbic acid reacts with $\mathrm{SO}_{2}$ at a ratio of $1: 1.7$ and not 1:1 as commonly assumed, and it therefore is important to first determine the existing concentration of ascorbic acid in the wine before making any ascorbic acid additions/adjustments (Nel \& Van Jaarsveld, 2018).

\section{CONCLUSIONS}

The results show that the accumulation of ascorbic acid derivatives varies between regions because of different climatic conditions. The conclusion is that there is close regulation of ascorbic acid biosynthesis, and the concentration in plant tissues is a result of balancing the synthesis with the catabolism of ascorbic acid. Catabolism would be the result of a breakdown of ascorbic acid to DHA, DKG, L-threonate and other compounds. In biological systems, ascorbic acid can be found only at low $\mathrm{pH}$, but in neutral solutions above $\mathrm{pH} 5$, it is predominantly found in its ionised form, as ascorbate, and this would deplete the total ascorbic acid concentration. The concentrations are high at E-L 32, and then decrease as the grapes ripen. Interestingly, threonic acid, one of the derivatives, had higher concentrations in almost all the stages of berry development, while the other derivatives, DHA and DKG, fluctuated between the stages. The reason could be that threonate is one of the last ascorbic acid derivatives and is highly stable under oxidation.

The accumulation of ascorbic acid derivatives was affected by the area in which the vines were planted, and Elgin had higher concentrations of ascorbic acid derivatives than Wellington at all the ripening stages. The concentrations of ascorbic acid derivatives were measured for both farms for a north-to-south and east-to-west vineyard orientation on both suckered and non-suckered vineyard rows. The results show that there were no significant differences between the suckered and non-suckered vineyard rows and that the vineyard rows did not show any effect on the accumulation of ascorbic acid derivatives. Although there were no significant differences between the vineyard blocks on each farm (Wellington and Elgin), there were significant differences in ascorbic acid derivatives between the two farms. The differences may be due to the climatic conditions to which the grapevines were exposed on each farm.

The pinking susceptibility of the wines, on the other hand, showed clear differences between regions, with wines vinified from Elgin grapes more highly susceptible to pinking than wines vinified in Wellington. Advancements in the field of ascorbic acid research have been accelerated by consumer interest in the nutritional value of this antioxidant. It is important to understand the mechanisms that determine the levels of ascorbic acid derivatives in fruits, a major source for ascorbic acid in the human diet. 


\section{LITERATURE CITED}

Andrea-Silva, J., Cosme, F., Ribeiro, L.F., Moreira, A.S., Malheiro, A.C., Coimbra, M.A., Domingues, M.R.M. \& Nunes, F.M., 2014. Origin of the pinking phenomenon of white wines. J. Agric. Food Chem. 62, 5651-5659.

Aziz, N.M. \& Sulaimani, K.I., 2013. Estimation some of metal ions and biological constituents of local rheum ribes (rhubarb) of Kurdistan region IRAQ. Chem. Mat. Res. 3(13), 27-31.

Badejo, A.A., Wada, K., Gao, Y., Maruta, T., Sawa, Y., Shigeoka, S. \& Ishikawa, T. 2011. Translocation and the alternative D-galacturonate pathway contribute to increasing the ascorbate level in ripening tomato fruits together with the D-mannose/L-galactose pathway. J. Exp. Bot., 63(1):229-239.

Baiano, A., De Gianni, A., Previtali, M.A., Del Nobile, M.A., Novello, V. \& De Palma, L., 2015. Effects of defoliation on quality attributes of Nero di Troia (Vitis vinifera L.) grape and wine. Food Res. Int. 75, 260-269.

Barril, C., Rutledge, D.N., Scollary, G.R. \& Clark, A.C., 2016. Ascorbic acid and white wine production: A review of beneficial versus detrimental impacts. Aust. J. Grape Wine Res. 22(2), 169-181.

Bradshaw, M.P., Barril, C., Clark, A.C., Prenzler, P.D. \& Scollary, G.R., 2011. Ascorbic acid: A review of its chemistry and reactivity in relation to a wine environment. Crit. Rev. Food Sci. Nutr. 51(6), 479-498.

Bradshaw, M.P., Scollary, G.R. \& Prenzler, P.D., 2004. Examination of the sulfur dioxide-ascorbic acid anti-oxidant system in a model white wine matrix. J. Sci. Food Agric. 84(4), 318-324.

Clingeleffer, P.R., 2010. Plant management research: Status and what it can offer to address challenges and limitations. Aust. J. Grape Wine Res. 16, $25-32$

Cojocaru, G.A. \& Antoce, A.O., 2015. Chemical and biochemical mechanisms of preservatives used in wine: A review. Scientific Papers. Series B. Horticulture, LVI, 457-466.

Coombe, B.G., 1995. Adoption of a system for identifying grapevine growth stages. Austr. J. Grape Wine Res. 1, 104-110.

Cruz-Rus, E., Amaya, I., Sanchez-Sevilla, J.F., Botella, M.A. \& Valpuesta, V., 2011. Regulation of L-ascorbic acid content in strawberry fruits. J. Exp. Bot. 62(12), 4191-4201.

Cruz-Rus, E., Botella, M.A., Valpuesta, V. \& Gomez-Jimenez, M.C., 2010. Analysis of genes involved in L-ascorbic acid biosynthesis during growth and ripening of grape berries. J. Plant Physiol. 167(9), 739-748.

Davey, M.W., Montagu, M.V., Inze, D., Sanmartin, M., Kanellis, A., Smirnoff, N., Benzie, I.J.J., Strain, J.J., Favell, D. \& Fletcher, J., 2000. Plant L-ascorbic acid: Chemistry, function, metabolism, bioavailability and effects of processing. J. Sci. Food Agric., 80(7), 825-860.

Davies, M.B., Partridge, D.A. \& Austin, J.A., 2007. Vitamin C: Its chemistry and biochemistry. London: Royal Society of Chemistry.

Deutsch, J.C., 1998a. Ascorbic acid oxidation by hydrogen peroxide. Anal. Biochem. 255(1), 1-7.

Deutsch, J.C., 1998b. Oxygen-accepting antioxidants which arise during ascorbate oxidation. Anal. Biochem. 265(2), 238-245

Dewhirst, R.A. \& Fry, S.C., 2015. The degradation of Vitamin C by reactive oxygen species (Poster presentation). Free Radic. Biol. Med. 86(Suppl. 1), S26

Du Plessis, K., Young, P.R., Eyéghé-Bickong, H.A. \& Vivier, M.A., 2017. The transcriptional responses and metabolic consequences of acclimation to elevated light exposure in grapevine berries. Front. Plant Sci. 8, 1261-1282.
Gautier, H., Diakou-Verdin, V., Bénard, C., Reich, M., Buret, M., Bourgaud, F., Poëssel, J.L., Caris-Veyrat, C. \& Génard, M., 2008. How does tomato quality (sugar, acid, and nutritional quality) vary with ripening stage, temperature, and irradiance? J. Agric. Food Chem., 56(4), 1241-1250.

Hamner, K.C., Bernstein, L. \& Maynard, L.A., 1945. Effects of light intensity, day length, temperature, and other environmental factors on the ascorbic acid content of tomatoes. J. Nutr. 29(2), 85-97.

Huang, M., Xu, Q. \& Deng, X.X., 2014. L-Ascorbic acid metabolism during fruit development in an ascorbate-rich fruit crop chestnut rose (Rosa roxburghii Tratt). J. Plant Physiol., 171(14), 1205-1216.

Iqbal, K., Khan, A. \& Khattak, M.M.A.K., 2004. Biological significance of ascorbic acid (vitamin C) in human health - A review. Pakistan J. Nutr. $3(1), 5-13$

Ishikawa, T., Dowdle, J. \& Smirnoff, N., 2006. Progress in manipulating ascorbic acid biosynthesis and accumulation in plants. Physiol. Plant. 126(3), 343-355.

Lee, S.K. \& Kader, A.A., 2000. Preharvest and postharvest factors influencing ascorbic acid content of horticultural crops. Postharvest Biol. Technol. 20(3), 207-220.

Levene, H., 1960. Robust tests for equality of variances. Contributions to probability and statistics: Essays in honor of Harold Hotelling. Stanford University Press, Palo Alto, CA.

Matei, N. 2008. Vitamin C determination in Murfatlar grapes in the ripening period. Ovidius Univ. Annals Chem. 19(1-2), 45-49.

Matei, N., Soceanu, A., Dobrinas, S. \& Magearu, V., 2009. Kinetic study of ascorbic acid degradation from grapes. Ovidius Univ. Ann. Chem. 20(1), 132-136.

Mellidou, I., Keulemans, J., Kanellis, A.K. \& Davey, M.W., 2012. Regulation of fruit ascorbic acid concentrations during ripening in high and low vitamin C tomato cultivars. BMC Plant Biol. 12(1), 12-239.

Nel, A.P., Du Toit, W.J. \& Van Jaarsveld, F.P., 2020. Pinking in white wines - A review. S. Afr. J. Enol. Vitic. 41(2), 151-157.

Nel, A.P. \& Van Jaarsveld, F.P., 2018. Guidelines to reduce pinking potential in white wines. Winetech Technical, Oenology Research. Available from https://www.wineland.co.za/guidelines-reduce-pinking-potential-whitewines/ [accessed 2 February 2020].

Ott, R.L., 1998. An introduction to statistical methods and data analysis. Duxbury Press, Belmont, CA.

Padayatty, S.J., Katz, A., Wang, Y., Eck, P., Kwon, O., Lee, J.H., Chen, S., Corpe, C., Dutta, A., Dutta, S.K. \& Levine, M., 2003. Vitamin C as an antioxidant: Evaluation of its role in disease prevention. J. Am. Coll. Nutr. $22(1), 18-35$.

Parsons, H.T. \& Fry, S.C., 2012. Oxidation of dehydroascorbic acid and 2, 3-diketogulonate under plant apoplastic conditions. Phytochem. 75, 41-49.

Pastore, C., Allegro, G., Valentini, G., Muzzi, E. \& Filippetti, I., 2017. Anthocyanin and flavonol composition response to veraison leaf removal on Cabernet Sauvignon, Nero d'Avola, Raboso Piave and Sangiovese Vitis vinifera L. cultivars. Sci. Hortic. 218, 147-155.

Penney, J.R. \& Zilva, S.S., 1945. The isolation of barium and calcium diketo-l-gulonates and the biological significance of 2: 3-diketo-1-gulonic acid. Biochem. J. 39(1), 1-4

Saito, K. \& Kasai, Z., 1969. Tartaric acid synthesis from L-ascorbic acid-114C in grape berries. Phytochem. 8(11), 2177-2182.

Saito, K. \& Loewus, F.A., 1979. The metabolism of L-[6-14C] ascorbic acid in detached grape leaves. Plant Cell Physiol. 20(8), 1481-1488. 
Shapiro, S.S. \& Wilk, M.B., 1965. An analysis of variance test for normality (complete samples). Biometrika 52(3/4), 591-611.

Shimada, Y. \& Ko, S., 2008. Ascorbic acid and ascorbic acid oxidase in vegetables. Chugokugakuen J. 7, 7-10.

Sidhu, D., Lund, J., Kotseridis, Y. \& Saucier, C., 2015. Methoxypyrazine analysis and influence of viticultural and enological procedures on their levels in grapes, musts, and wines. Crit. Rev. Food Sci. Nutr. 55(4), $485-$ 502 .

Simpson, R.F., 1977. Pinking in Australian white table wines. Vitis 16, 286 294.

Singleton, V.L., 1972. Common plant phenols other than anthocyanins, contributions to coloration and discoloration. Adv. Food. Res. Suppl. 143191.

Skouroumounis, G.K., Kwiatkowski, M.J., Francis, I.L., Oakey, H., Capone, D.L., Duncan, B., Sefton, M.A. \& Waters, E.J., 2005a. The impact of closure type and storage conditions on the composition, colour and flavour properties of a Riesling and a wooded Chardonnay wine during five years' storage. Aust. J. Grape Wine Res., 11(3), 369-377.

Skouroumounis, G.K., Kwiatkowski, M.J., Francis, I.L., Oakey, H., Capone, D.L., Peng, Z., Duncan, B., Sefton, M.A. \& Waters, E.J., 2005 b. The influence of ascorbic acid on the composition, colour and flavour properties of a Riesling and a wooded Chardonnay wine during five years' storage. Aust. J. Grape Wine Res. 11(3), 355-368.

South Africa Explorer, 2017. Grabouw climate. Available from http://www. saexplorer.co.za/south-africa/climate/grabouw_climate.asp [accessed 20 May 2019].
Stofberg, A., 2018. The effect of irrigation scheduling on the performance of young apple trees in newly established orchards. Dissertation, Stellenbosch University, Private Bag X1, 7602 Matieland (Stellenbosch), South Africa.

Svirbely, J.L. \& Szent-Györgyi, A., 1932. The chemical nature of ascorbic acid. Biochem. J. 26(3), 865-870.

Truffault, V., Fry, S.C., Stevens, R.G. \& Gautier, H., 2017. Ascorbate degradation in tomato leads to accumulation of oxalate, L-threonate and oxalyl L-threonate. Plant J. 89(5), 996-1008.

Tswane, S., Korpela, M., M'Rithaa, D.K.M. \& Kabaso, B., 2014. The maternal healthcare landscape around Grabouw, South Africa: Setting the stage for information systems development. J. Health Inform. Afr. 2(2), 7375 .

Wechtersbach, L., Polak, T., Ulrih, N.P. \& Cigić, B., 2011. Stability and transformation of products formed from dimeric dehydroascorbic acid at low pH. Food Chem. 129(3), 965-973.

Yang, J.C. \& Loewus, F.A., 1975. Metabolic conversion of L-ascorbic acid to oxalic acid in oxalate-accumulating plants. Plant Physiol. 56(2), 283-285 Young, P.R., Eyeghe-Bickong, H.A., Du Plessis, K., Alexandersson, E., Jacobson, D.A., Coetzee, Z., Deloire, A. \& Vivier, M.A., 2016. Grapevine plasticity in response to an altered microclimate: Sauvignon blanc modulates specific metabolites in response to increased berry exposure. Plant Physiol. $170(3), 1235-1254$

Yu, R., Cook, M.G., Yacco, R.S., Watrelot, A.A., Gambetta, G., Kennedy, J.A. \& Kurtural, S.K., 2016. Effects of leaf removal and applied water on flavonoid accumulation in grapevine (Vitis vinifera L. cv. Merlot) berry in a hot climate. J. Agric. Food Chem. 64(43), 8118-8127. 